\title{
Museums need two cultures
}

\section{The resignation of the head of the Smithsonian Institution highlights a misguided tendency for museums to focus on communication at the expense of research. It also offers the chance of a fresh start.}

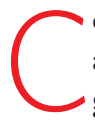
orporate managers like mission statements; scientists generally don't. Academic freedom often sits uneasily alongside the the private sector Researchers would prefer not to be told what to do. It's interesting, therefore, that scientists at the Smithsonian Institution are so proud of their mission statement - especially as they have only just welcomed the resignation of Larry Small, a leader who angered many by trying to impose a corporate ethos on the organization (see page 594).

But the vision they share is not that espoused by the departing Small. They are proud instead to recite the mission statement of the British scientist James Smithson, who funded the creation of their institution in 1846 for the "increase and diffusion of knowledge". Small seemed either to not understand, or to not care too much, about the fact that the museum should remain committed to both public outreach and to new research. Worryingly, the leaders of some other prominent museums also have this fault.

The scientists' desire to fulfil both strands of Smithson's vision is notable. Many researchers in purely academic institutions often shy away from outreach work. Some lack the skills. Others fear, often rightly, that funders will not reward them for time spent communicating what they do. Museums such as the Smithsonian are among the only places where scientists are required to do both. They are historical oddities, as it is now extremely rare for such dual-purpose organizations to be created. Yet the combination of missions leads to a special form of science communication.

When outside professionals are drafted in to build exhibits, as is the trend in many natural-history and science museums, there are benefits. But there are also risks unless professional researchers continue to play a leading role. Be they palaeobiologists or historians of science, their involvement should lead to the creation of exhibits that intimately reflect the science behind the display in a way that other forms of science communication, such as science writing, cannot.
Some of these displays are now badly dated, but the galleries of dusty fossils that gave scientific curators a bad name were dumped years ago by the more innovative institutions.

The Natural History Museum in London, for example, is creating a centre that will allow visitors to see parts of the museum's extraordinary research collections and to interact with the scientists who work on them. At the Smithsonian, researchers want to channel real-time data from animal monitoring experiments at the institution's field stations into exhibits about the species involved.

Such projects happen naturally in organizations that do both science and science communication, yet the research side of many of these institutions is suffering. Small paid too little heed to it during his seven years at the Smithsonian. The collections division at the Science Museum in London, which houses curators who also do historical research, has been gutted over the past 20 years. In others, such as the Academy of Natural Sciences in Philadelphia, which is profiled on page 605 , parts of the collection have been sold to make up for funding shortfalls.

This gloomy trend now needs to be reversed, and there are signs of hope. For example, the new head of the Philadelphia academy, ornithologist William Brown, has a track record of valuing
"Researchers can create exhibits that reflect the science in ways that other forms of science communication cannot." and understanding science. As the Smithsonian's regents begin their search for a successor to Small, they should look at Brown's plans, or those of London's Natural History Museum, because museums that combine science and outreach are vibrant and unique places. Exhibits get the media attention and attract donors. But take away the in-house scholars who help build them, and museums take another step towards becoming little more than theme parks.

and logged systematically, could play a role in supporting species (see page 608).

For many long-time observers of conservation issues, the initial response to such a project may be to roll their eyes and think: "Here we go again." There have, after all, been many timber companies - particularly ones operating in Indonesia, which takes up most of the rest of Borneo - that claimed to be logging 'sustainably' when in fact they were destroying natural forests.

Such scepticism is understandable, but it doesn't make the Sarawak project unworthy of support. Indeed its design gives some grounds for optimism. The conservation biologists involved in it have some economic leverage, as timber companies are subject to increasing pressure from buyers to supply timber that is grown and logged in ways that minimize environmental impact. This was probably the conservation zone. The biologists in charge of the conservation zone are optimistically thinking that even the plantation zone, if designed 